surprising that publishers try to compile such directories at all. What they should do of course - and what in fact Wiley do now do - is to provide the information through on-line databases. These are much easier to keep up to date and can be searched far more effectively than their printed counter parts.

The price paid for broadening the geography, while keeping the general scope, is a loss of detail. Longman's Medical Research Centres covers 11,000 laboratories and organizations including charities, commercial laboratories and individual university departments worldwide, arranged alphabetically and by country. A broad idea of the interests of each one can be obtained, quite often together with the yearly budget. Commercial laboratories seem a bit coy about theirs. Again in those areas where I had detailed, up-to-date information, I found these volumes tended to be out-of-date - and sometimes things were not spelt out very well. My favourite entry, other than Dr Iversen's traditional two, was that the Medical Research Council employs 106.5 million graduate staff. The head of personnel is right to worry about overmanning!

My favourite among all these four works, though, is Saur Verlag's World Guide to Scientific Associations and Learned Societies, one volume listing 22,000 organizations in all fields, science, technology and the other cultures; very catholic, I could have read it for hours. Here one encounters the American Underground-Space Association (not hollowearthers, but engineers). And what about the Disinfected Mail Study Circle or the Japanese Correctional Association - it may just refer to the language but I am not sure. This book seemed to me to be truly valuable as a means to cultural insight, but most of the entries are in the language of their country of origin and are usually not translated. Also provided is an 8,000 -entry index of the abbreviations for the associations, and then a breakdown by subject, another fascinating compilation. Under humanities, Britain rates only one entry along with Togo, Upper Volta, Iran and Israel, whereas France has 16 and the USSR none.

There is a fair overlap between this volume and the excellent The World of Learning, published by Europa, which lists 24,000 universities, museums and learned societies, for instance, and gives a fair amount of detail about each, managing to get in roughly 150,000 of the people associated with them; a new edition for 1984-5 comes out soon. But the strength of Saur's World Guide is its breadth - the placing of the large "official" organizations in a proper context of grass-roots societies. Science indeed is more than main-stream institutional research.

John Galloway is at the Medical Research Council's Headquarters in London.

\section{China: the promise and the problems}

\section{Gregory Blue}

Science and Technology in China.

By Tong B. Tang.

Longman: 1984. Pp. 269. £45, \$85.

CHINA'S science and technology have developed rapidly since 1949 , and in particular since the National Science Policy Conference of March 1978 which aimed at bringing China to advanced international levels by the year 2000 . In this contribution to Longman's Guide to World Science and Technology series, Tong B. Tang (Deng Tang-bo) presents us with a concise, up-todate account of the state of play in those fields of applied science and sophisticatedto-intermediate technology designated for priority development at that conference. This volume thus nicely complements the collaborative work, Science in Contemporary China edited by Leo A. Orleans (Stanford University Press, 1980), which surveyed the entire range of pure and applied sciences down to the end of the 1970s.

Following a general introductory analysis of science policy, organization and funding, the author proceeds in subsequent chapters to examine agricultural and environmental research, the earth sciences and mineral industries, energy science and technologies, as well as transportation and information technologies. For the chapter devoted to the biomedical sciences valuable contributions have been elicited from Hong Guo-Fan and Jin Neng-Ren, who write respectively about basic research and clinical practice. An interpretive sketch on science and social change in China by John Collier fills in the basic historical background in Chapter 2 . The final chapter helpfully (though unusually) gives an exposé of the state of science and technology in Taiwan. One might also have liked to see included a similar chapter on Hong Kong (Xianggang, in the pinyin rendering of the standard pronunciation); but this is not a serious lack, since knowledge of work done there is already quite accessible.

The author takes due care to identify key institutes, to note which ones have been reorganized in recent years and to describe in some detail the work being done at each. Indication is given of those areas (such as microsurgery, earthquake prediction and satellite tracking and recovery) in which Chinese scientists have already attained advanced world levels. The author also points out that, having started from a very restricted industrial base before 1949 , China has recently overtaken Japan as the world's foremost manufacturer of radios; she also now ranks as the fifth-largest producer of steel, although certain highgrade types still remain beyond her competence. As in the Soviet Union, performance in the pure sciences is generally impressive. Like both the Soviet Union and Japan, however, China faces considerable problems in several areas in moving from basic research through the realm of research and development and into that of economic operationality. And Chinese technological capacity remains low in some crucial economic sectors. For example, in the coal industry $40 \%$ of pit faces are still unmechanized; and there are grave shortages in the transportation and energy sectors. Given present priorities, however, such circumstances may well be dramatically changed by the end of the century.

Chinese modernization in the early postMao years was predicated on a policy of massive and sometimes ill-considered technology transfer from the industrialized countries. In recent years this policy has been replaced by one of more selective transfer, often under the auspices of agencies of the United Nations. Emphasis seems to have swung towards importing a restricted number of examples of a particular technology and of using native expertise to appropriate it to Chinese conditions.

One supposes that, after a lag of several centuries, the task of bringing Chinese scientific and technological standards back up to international levels in most major fields will require a few generations more. Much progress has already been booked, however; in the light of China's human resources and history, it would be surprising if it were not to continue. At present it would seem ill-considered to keep oneself in the dark about the work of Chinese scientists, for there are few fields in which they have not made significant breakthroughs, as the volume under review shows.

Despite the diversity of its technical subject-matter, the presentation in Science and Technology in China is clear, concise and in general easily readable, though perhaps more attention at the sub-editing stage would have been in order. Conscientious internal cross-referencing together with efficient subject - and institutional - indexes make it a useful reference work.

Gregory Blue is a research associate at the Needham Research Institute, Cambridge, UK and a collaborator on the Science and Civilisation in China project.

- Other titles published in the Longman Guide to World Science and Technology series deal with the Middle East (by Ziauddin Sardar; reviewed in Nature 302, 359; 1983), Latin America (compiled by Latin American Newsletters) and, most recently, Japan (by Alun M. Anderson).

Later volumes will cover the United Kingdom, South-East Asia, the Indian Subcontinent, the United States, and Australasia, Antarctica and the Pacific. 